\title{
A Modified Boston Bowel Preparation Scale After Colorectal Surgery
}

\author{
Lorenzo Dioscoridi, Edoardo Forti, Francesco Pugliese, Marcello Cintolo, Angelo Italia, Marta Bini, \\ Giulia Bonato, Aurora Giannetti, Massimiliano Mutignani \\ Digestive and Interventional Endoscopy Unit, ASST Niguarda, Milan, Italy
}

To the Editor,

We read with great interest the article "Bowel preparation for surveillance colonoscopy after colorectal resection: a new perspective" by Lee and Chun [1]. We would like to focus on the importance of standardization of quality bowel preparation in patients. This quality is related to risk of adenomatous/neoplastic polyp development in such cluster of patients than in the general population and to need for oncological follow-up $[2,3]$. We agree with the authors in using the Boston Bowel Preparation Scale (BBPS) to define quality in such patients.

It is important, however, to clarify that the total score of these patients has to be modified according to type of surgery:

- Six points for patients after hemicolectomy (left, right, extended right), transverse colectomy, anterior rectal resection (standard, low, ultra low, Hartmann procedure), or abdominalperianal resection (Miles' operation). After these types of surgery, two segments of colon remain (according to the tracts considered in BBPS).

- Three points for patients after total/subtotal colectomy because only the lower tract remains after these types of surgery (according to the tracts considered in BBPS).

We agree that several factors are involved in bowel preparation in operated patients; increased speed of stool passage (especially in the first year after surgery and/or after recanalisation) and absence of the ileocecal valve are two of the most important to be considered.

We applied this BBPS in our hospital and have standardized (from January 2016 to January 2019) the operation in 1,237 colo-

Received: Aug 20, 2019 - Revised: Aug 20, 2019 • Accepted: Aug 20, 2019 Correspondence to: Lorenzo Dioscoridi, M.D., Ph.D.

Digestive and Interventional Endoscopy Unit, ASST Niguarda, Piazza

Ospedale Maggiore 3, 20162 Milan, Italy

Tel: +39-3334950733

E-mail dioscoridi.lorenzo@virgilio.it

ORCID: https://orcid.org/0000-0003-4975-018X

(C) 2021 The Korean Society of Coloproctology

This is an open-access article distributed under the terms of the Creative Commons Attribution NonCommercial License (https://creativecommons.org/licenses/by-nc/4.0) which permits unrestricted noncommercial use, distribution, and reproduction in any medium, provided the original work is properly cited. noscopy patients (612 after left hemicolectomy, 284 after right colectomy, 219 after anterior rectal resection, 73 after abdominalperianal resection, 49 after total colectomy). We report good bowel preparation (minimum score of 2 for all segments) in $76.5 \%$ of patients after left hemicolectomy (in line with the reported data from the article), $65.6 \%$ of patients after right hemicolectomy, $78.9 \%$ of patients after anterior rectal resection, $82.3 \%$ of patients after abdominal-perianal resection, and $98.7 \%$ after total colectomy. The results are in line with the previously described data.

In conclusion, we confirm the data reported by our colleagues and the importance of standradization of bowel preparation in operated patients according to the BBPS.

\section{CONFLICT OF INTEREST}

No potential conflict of interest relevant to this article was reported.

\section{REFERENCES}

1. Lee D, Chun HK. Bowel preparation for surveillance colonoscopy after colorectal resection: a new perspective. Ann Coloproctol 2019;35:129-36.

2. Kahi CJ, Boland CR, Dominitz JA, Giardiello FM, Johnson DA, Kaltenbach T, et al. Colonoscopy surveillance after colorectal cancer resection: recommendations of the US multi-society task force on colorectal cancer. Gastrointest Endosc 2016;83:489-98.

3. le Clercq CM, Winkens B, Bakker CM, Keulen ET, Beets GL, Masclee AA, et al. Metachronous colorectal cancers result from missed lesions and non-compliance with surveillance. Gastrointest Endosc 2015;82:325-33. 